\title{
High-Intermediate Risk Mantle Cell Lymphoma International Prognostic Index Combined Biologic Index
}

National Cancer Institute

\section{Source}

National Cancer Institute. High-Intermediate Risk Mantle Cell Lymphoma International

Prognostic Index Combined Biologic Index. NCI Thesaurus. Code C137809.

Intermediate risk MIPI score (4-5) and Ki-67 greater than or equal to $30 \%$ or High risk MIPI score (6-11) and Ki-67 less than 30\%. A MIPI-c high-intermediate risk equals a MIPIc score of 2. 